\title{
Understanding the Link Between Maternal Overnutrition, Cardio-Metabolic Dysfunction and Cognitive Aging
}

\author{
Daria Peleg-Raibstein*
}

Laboratory of Neurobehavioural Dynamics, Institute for Neuroscience, Department of Health Sciences and Technology, ETH Zürich, Zürich, Switzerland

\section{OPEN ACCESS}

Edited by:

Gustavo Pacheco-Lopez, Autonomous Metropolitan University,

Lerma, Mexico

Reviewed by:

Salvador Villalpando,

Federico Gómez Children's Hospital,

Mexico

Virve Cavallucci,

Agostino Gemelli University Polyclinic,

Catholic University of the Sacred

Heart, Italy

*Correspondence:

Daria Peleg-Raibstein

daria-peleg@ethz.ch

Specialty section:

This article was submitted to

Neuroenergetics, Nutrition and Brain

Health,

a section of the journal

Frontiers in Neuroscience

Received: 23 December 2020

Accepted: 10 February 2021

Published: 26 February 2021

Citation:

Peleg-Raibstein D (2021)

Understanding the Link Between

Maternal Overnutrition,

Cardio-Metabolic Dysfunction

and Cognitive Aging.

Front. Neurosci. 15:645569.

doi: 10.3389/fnins.2021.645569
Obesity has long been identified as a global epidemic with major health implications such as diabetes and cardiovascular disease. Maternal overnutrition leads to significant health issues in industrial countries and is one of the risk factors for the development of obesity and related disorders in the progeny. The wide accessibility of junk food in recent years is one of the major causes of obesity, as it is low in nutrient content and usually high in salt, sugar, fat, and calories. An excess of nutrients during fetal life not only has immediate effects on the fetus, including increased growth and fat deposition in utero, but also has long-term health consequences. Based on human studies, it is difficult to discern between genetic and environmental contributions to the risk of disease in future generations. Consequently, animal models are essential for studying the impact of maternal overnutrition on the developing offspring. Recently, animal models provided some insight into the physiological mechanisms that underlie developmental programming. Most of the studies employed thus far have focused only on obesity and metabolic dysfunctions in the offspring. These studies have advanced our understanding of how maternal overnutrition in the form of high-fat diet exposure can lead to an increased risk of obesity in the offspring, but many questions remain open. How maternal overnutrition may increase the risk of developing brain pathology such as cognitive disabilities in the offspring and increase the risk to develop metabolic disorders later in life? Further, does maternal overnutrition exacerbate cognitive- and cardio-metabolic aging in the offspring?

Keywords: maternal, obesity, overnutrition, cardiovascular disease, offspring, animal models, cognition, aging

\section{INTRODUCTION}

The prevalence of obesity is increasing worldwide and has reached epidemic proportions posing a major problem for healthcare (Ng et al., 2014; Hruby and Hu, 2015). The last World Health Organization (WHO) report classified 1.9 billion adults worldwide as overweight and more than 650 million as obese (WHO, 2020). Obesity is associated with an increased incidence of comorbidities like dyslipidemia, hypertension and type 2 diabetes mellitus (T2DM; Hruby and $\mathrm{Hu}, 2015)$. These conditions are associated with higher cardiovascular disease risk and 
mortality. A particular concern emerged in the past two decades, namely obesity during pregnancy (Heslehurst et al., 2010; Huda et al., 2010; Gregor et al., 2016; Lindberg et al., 2016; Kominiarek and Peaceman, 2017). Nearly two thirds of women of childbearing age (19-44) are overweight and 36.5\% are obese. It is therefore not surprising that this epidemic also affects children of all ages with nearly 38 million children under the age of 5 years classified as overweight or obese (WHO, 2020). It is already known that the obesity epidemic cannot be explained only as a result of an affluent lifestyle, reduced physical activity or a genetic predisposition (Albuquerque et al., 2017; Sheikh et al., 2017). Evidence has suggested that it may originate from environmental factors present already early in development during fetal life. In the early 1980s the Barker hypothesis, also referred as the "developmental origins of adult disease," alluded to an association between fetal undernutrition and low birth weight with the risk of developing adult obesity, including the metabolic syndrome and cardiovascular disease (Barker et al., 1990; Barker, 2007). Programming is a process whereby an insult at a critical time period of development has lifelong significance. According to the Barker hypothesis, variations in the transfer of food from the mother to her baby have profound and long-term implications for the health of the next generation (for review see McMillen et al., 2005). Since the original observations of David Barker, various human and animal studies shifted their investigations to studying the effects of maternal overnutrition and obesity, since diets high in calories and fats combined with limited physical activity and increased sedentary behavior have become more prevalent in developed as well as under-developed countries. Conforming to this hypothesis, studies in the past two decades suggested a link between maternal obesity and/or overnutrition during pregnancy and the increase risk of obesity later in life (Kominiarek and Chauhan, 2016). Epidemiological studies report a positive relationship between weight at birth and adult body mass index (BMI). Moreover, maternal BMI, in particular its increase during pregnancy is positively related to obesity in the offspring as babies, through childhood and into adulthood (Lawlor et al., 2007). More specifically, in a United States cohort, maternal first-trimester obesity led to a two- to threefold increase in the risk of childhood obesity in their progeny; $24 \%$ of the children of obese mothers were themselves obese at age 4 , compared with $9 \%$ of the children of normal-weight mothers (Whitaker, 2004). A maternal hypernutritional state, due to pre-existing T2DM, gestational diabetes or obesity, generates a long-term risk of obesity for the child. Gestational weight gain, irrespective of pre-pregnancy body mass, is positively associated with obesity in 3 years old children (Oken et al., 2007). Maternal obesity increases a child's risk for developing obesity as a consequence of either shared genes, environmental factors, or a combination of both. Parents not only create food environments for their children but also influence their eating behaviors, taste preferences, and food choices (Kral and Rauh, 2010). The in utero environment, which profoundly affects the fetal developmental processes, is considered as important as genes or family habits in determining the predisposition to long-term health outcomes. Thus, the in utero environment is a key player leading to increased risk of obesity, T2DM and cardiovascular disease in the adult offspring upon exposure to increased nutrient supply before birth (Reynolds et al., 2013; Godfrey et al., 2017). A relation between different insults during pregnancy, including famine, different types of infections, prenatal stress, obstetric complications, smoking, were shown to impact the adult life of the progeny (Boksa, 2004). However, it appears virtually impossible in human studies to establish a cause-effect relationship, to disentangle the direct effects of maternal obesity from the influence of shared genes and postnatal lifestyle on the developing child. Therefore, animal models are necessary to answer these crucial questions and generate results that then may be translated to humans.

This review will summarize findings on the long-term effects of maternal overnutrition and obesity on metabolic states and cognitive function in the offspring from human and rodent studies. It will also try to identify whether one trait can be the consequence of the other.

\section{THE MATERNAL OVERNUTRITION/OBESITY ANIMAL MODEL}

Maternal obesity can be induced by exposing female animals to different nutritional diets for example hyperenergetic and highly palatable diets such as high-fat (varying between 45 and 60\% calories from fat) (Tozuka et al., 2009, 2010; Peleg-Raibstein et al., 2012, 2016; Kang et al., 2014; Graf et al., 2016; Janthakhin et al., 2017; Robb et al., 2017; Sarker and Peleg-Raibstein, 2018; Sarker et al., 2018, 2019a,b; Wolfrum and Peleg-Raibstein, 2018; Moreton et al., 2019; Zieba et al., 2019), a combination of highfat high-sugar diet, high-sugar diet or a cafeteria diet which supplement the normal chow diet with a variety of palatable foods (Wright et al., 2014; Ribeiro et al., 2018; Lewis et al., 2019; Moreton et al., 2019). These different diets promote weight gain and depending on the length of exposure induce obesity and other metabolic disorders to the mother. These diets are trying to mimic the human modern food habits and consumption. Each of these types of diets have their advantages and disadvantages. For example, in the high-fat diet (HFD) and high-fat high-sugar diet (HFHS) models, the macronutrients and micronutrients contents can be controlled between the obesogenic diets and the control chow diet. They are commercially available and can be easily utilized. Whereas, the cafeteria diet model has different variations depending on the laboratory and can be tailored depending on the specific research question and adapted accordingly. Female mice exposed to the cafeteria diet gain faster body weight and develop increased body fat composition with changes of other metabolic markers (i.e., insulin levels, triglycerides levels etc.) compared to the HFD model. However, in this diet it is more difficult to control for intake of macronutrients and micronutrients. In addition, by using this diet one needs more careful planning and executing of the diet schedules because otherwise the changes in diet composition throughout the experiment will have too much variations.

An overview of the current literature on animal studies investigating the effects of maternal obesity or overnutrition 
utilizes different maternal diets (as mentioned above) as well as different exposure time periods such as exposure only during gestation, only during lactation or prior to mating (conception) and during gestation and lactation (Ghosh et al., 2001; Siemelink et al., 2002; Buckley et al., 2005; Gregersen et al., 2005; Khan et al., 2005; Chen et al., 2008, 2009; Naef et al., 2008, 2011; Dunn and Bale, 2009, 2011; Elahi et al., 2009; Morris and Chen, 2009; Niculescu and Lupu, 2009; Tamashiro et al., 2009; White et al., 2009; Bilbo and Tsang, 2010; Chechi et al., 2010; Gregorio et al., 2010; Vucetic et al., 2010; Ashino et al., 2011; Dunn et al., 2011; Simar et al., 2011; Strakovsky et al., 2011; Wahlig et al., 2011; Zhang et al., 2011; Peleg-Raibstein et al., 2012, 2016; Vogt et al., 2014; Sarker and Peleg-Raibstein, 2018; Sarker et al., 2018, 2019a,b; Wolfrum and Peleg-Raibstein, 2018; Zieba et al., 2019). In addition, also the time periods of exposure prior to mating differ between the studies. Thus, these studies have led to considerably inconsistent metabolic and behavioral outcomes in the offspring.

\section{THE LONG TERM-EFFECTS OF MATERNAL OVERNUTRITION ON COGNITIVE FUNCTION OF THE OFFSPRING}

With rates of global obesity constantly increasing, maternal obesity, and excessive gestational body weight leading not only to obesity but also to other long-term health outcomes such as cardiovascular disease and mental disorders including cognitive decline in the progeny. In the past few years, human studies linked maternal obesity with cognitive abnormalities in the offspring (for review, Van Lieshout, 2013; Contu and Hawkes, 2017). More specifically, maternal obesity was linked to reduction in child intelligence quotient (IQ) scores (Neggers et al., 2003; Gage et al., 2013; Bliddal et al., 2014; Pugh et al., 2015), cognitive test scores (Tanda et al., 2013), impaired neuropsychological development (Hinkle et al., 2012; Casas et al., 2013; Huang et al., 2014) and autism spectrum disorder and other intellectual disabilities (Brion et al., 2011; Li et al., 2016; Kong et al., 2020) in the children. Additionally, other studies suggested that an association might exist between maternal obesity and increased symptoms of attention-deficit hyperactivity disorder (ADHD) in children (Rodriguez et al., 2008; Rodriguez, 2010; Buss et al., 2012; Jenabi et al., 2019; Kong et al., 2020; Li et al., 2020; Robinson et al., 2020). Although the association between maternal obesity and offspring's cognitive disabilities was described, the current literature is still scarce, and findings are inconsistent (Brion et al., 2011; Keim and Pruitt, 2012; Van Lieshout, 2013; Bliddal et al., 2014). The underlying mechanisms leading to a higher susceptibility of the progeny to develop cognitive abnormalities later in life is still unknown. The observed cognitive impairments in the adult offspring could also be a result of obesity. Therefore, the understanding how maternal weight and weight gain might contribute to offspring's cognitive development is important, however, knowledge gaps remain. It was shown that excessive food intake and obesity leads to increased risk for cognitive impairments and to various types of neurodegenerative dementia (Stranahan and Mattson, 2008; Sellbom and Gunstad, 2012; Wraw et al., 2018). Therefore, to date, it is still not clear whether the cognitive decline is a trait that precede obesity and/or the metabolic syndrome, or whether the metabolic state itself is leading to cognitive disabilities. Another important question is whether maternal overnutrition exacerbate aging, metabolically and cognitively in subsequent generations.

Maternal nutrition is important for an optimal neurodevelopment of the offspring. In recent years, an increased interest emerged looking at the effects of maternal nutrition and offspring cognitive function. When assessing learning and memory, most of the studies investigated the effects of maternal overnutrition and obesity by examining hippocampal-dependent learning and memory mainly employing the Morris water maze paradigm. Bilbo and Tsang (2010) demonstrated that maternal diet high in either saturated or trans fats induced increased spatial memory performance and a concomitant increased inflammation within the hippocampus compared to control offspring. In contrast, decreased spatial memory performance in the Barnes maze was found in young and adult offspring born to obese mothers (Tozuka et al., 2010). Similar impaired spatial memory performances were observed in offspring exposed to a HFD throughout both the pre- and postnatal period (White et al., 2009; Page et al., 2014; Lépinay et al., 2015). Working memory assessment employing the novel object recognition task also lead to contradictory findings between studies. One study described reduced novel object exploration in young adult offspring exposed to maternal HFD (MHFD) (Graf et al., 2016) while offspring exposed to maternal cafeteria diet during lactation reported increased novel object exploration (Wright et al., 2014). Another study employing exposure led to a wide spectrum of cognitive abnormalities in an age-depend manner in the offspring (Wolfrum and Peleg-Raibstein, 2018). The behavioral abnormalities observed in the adult offspring readily suggests that the perturbations caused by MHFD exposure are diverse and fundamental to normal brain development. It was shown that offspring exposed to MHFD were severely impaired in acquisition of avoidance learning in an aversive learning task, a two-way active avoidance paradigm, as compared to control offspring at adulthood (Wolfrum and Peleg-Raibstein, 2018) while working memory and fear memory remained intact (PelegRaibstein et al., 2012; Wolfrum and Peleg-Raibstein, 2018) during adulthood and impaired in aged-adult HFD offspring (Wolfrum and Peleg-Raibstein, 2018). This study had several unique strengths: the longitudinal nature allowed to assess offspring cognition at different developmental ages utilizing different behavioral cognitive testing. The authors could pinpoint when different cognitive dysfunctions such as working memory, spatial memory and associative memory were evident. In summary all these findings can show that cognitive abilities can be influenced by obesity of the offspring. Most of these behavioral tests are dependent of hippocampus function (Vorhees and Williams, 2014). A brain region important in cognitive processing, learning and memory and that was also shown to be sensitive to changes in dietary energy intake (Miller and Spencer, 2014) and in aged-related cognitive ability (Gerstein et al., 2013). In addition, 
it was shown that exposure to a high-calorie diet in middle-aged rats led to impaired hippocampus-dependent cognitive functions such as spatial learning and which was accompanied by reduced hippocampal neurogenesis and synaptic plasticity (Stranahan et al., 2008). Since the development of the hippocampus is sensitive to in utero nutritional insults, it is not surprising that maternal HFD induced cognitive function impairments which was associated with inhibition of hippocampal neurogenesis and increased apoptosis in the offspring (Tozuka et al., 2009; Kim and Park, 2018).

These discrepancies might be due to methodological differences between the studies such as different gender used, timing of maternal dietary exposure, strain of the animals, different maternal diets employed, different testing protocols and age of the offspring at the time of testing. Another important consideration for the interpretation of the findings is that not all of the maternal diets utilized induce differences in gestational weight between female dams exposed to diet-induced obesity or control diet with no difference in any other metabolic parameters [i.e., fat mass, plasma glucose, insulin, triglycerides, cholesterol, and FFA levels (Peleg-Raibstein et al., 2016)]. While other animal models of maternal obesity lead to an obese state of the mothers (Bilbo and Tsang, 2010; Tozuka et al., 2010; Simar et al., 2011). This makes it difficult to dissociate between the direct effect of maternal obesity and that of overnutrition leading to obesity in the offspring.

Until now, relatively little is known about how maternal overnutrition/obesity can lead to lifelong consequences in cognitive abilities of the offspring. In this respect, this field of research is still in its early stages, and additional studies are required to examine the long-term effects of maternal overnutrition/obesity on memory and learning abilities of the offspring that may lead to advanced cognitive aging and also to increased risk to develop Alzheimer's disease (AD).

\section{NUTRITIONAL PROGRAMMING OF ALZHEIMER'S DISEASE AND RELATED COGNITIVE DECLINE}

To this date, investigations on the impact of maternal overnutrition and maternal obesity on offspring cognitive performance and mental health in animal models have focused mainly on anxiety, depression and motivation with some newer studies also examining the effects on learning and memory. Alzheimer's disease, the most common form of dementia, is a chronic progressive neurodegenerative disorder that develops slowly over decades. The observable pathological brain changes and the symptoms often do not follow the same time-course, which makes the diagnosis difficult. One of the clinically observed symptoms is memory loss, with the hippocampus and the cerebral cortex being the brain regions primarily involved. Interestingly, classic clinical studies indicate that human $\mathrm{AD}$ is also associated with damage in brain areas related to nutrient-sensing and the motivation to move, especially the hypothalamus which is also linked to the ability to form memories (Ishii, 1966; Saper and German,
1987). The exact etiology of AD is still not fully understood, however, ample evidence points to amyloid-beta peptide $(\mathrm{A} \beta)$ as a key player in the pathogenesis of $\mathrm{AD}$ and is the earliest lesion in the disease process (Hardy and Higgins, 1992; Ballard et al., 2011). In the past, $A D$ was thought to be a disease that developed in later life, but there is increasing evidence that the disease probably begins many years before clinical symptoms appear. Thus far, very little is known about this "silent" stage of the disease. Exactly when AD begins, and why some people get it and others do not, is still not fully understood. There are many environmental risk factors, such as nutrition, that are thought to have their major effects long before the disease can be diagnosed (Killin et al., 2016). For example, elevated dietary intake of fat has been shown to increase the risk of developing $\mathrm{AD}$ and facilitate age-related cognitive impairments (Luchsinger et al., 2002; Hooijmans and Kiliaan, 2008; Gustafson, 2012). Therefore, it is not surprising that obesity and consumption of a Western-style diet, especially in mid-life, are associated with increased risk of $\mathrm{AD}$ later in life (Laitinen et al., 2006). The prevalence of AD is greater in countries with a high intake of high-fat/high-calorie diets and lower in those that consume low-fat diets (Grant, 1999; Panza et al., 2004). Recently, evidence suggests that maternal diet may also impact accelerating aging and (McAninch et al., 2020 ) the subsequent appearance of $\mathrm{AD}$ in late life (Borenstein et al., 2006; Lahiri et al., 2008; Miller and O'Callaghan, 2008; Tolppanen et al., 2016). In the previous section we discussed the association from human studies and evidence from preclinical animal models between maternal obesity and unhealthy eating with cognitive impairments and disturbances of cerebral cortex and hippocampus function (Van Lieshout et al., 2011; Van Lieshout, 2013; Cordner and Tamashiro, 2015; Contu and Hawkes, 2017). These leads to neuropsychological impairments as deficits in attention, working memory and executive function. However, to date the underlying mechanisms linking maternal diet to these pathophysiological changes of the brain and behavior are not fully understood. As obesity is a risk factor for $\mathrm{AD}$ and excessive intake of fats in adulthood worsen $\mathrm{AD}$ in animal models (Tolppanen et al., 2016; Baranowski et al., 2018; Lloret et al., 2019), it is possible that maternal overnutrition affects the development of $\mathrm{AD}$ in the offspring. Animal models are fundamental for our understanding the effects of an obesogenic environment during fetal life and the effects depend on multiple and not-exclusive pathways that may lead to long-term neuropathological outcomes. Thus, by employing the overnutrition/obesity animal model with a common genetic background, carefully controlled dietary and activity conditions and a controlled postnatal environment is fundamental for examining how overnutrition prior and during pregnancy increases the development of obesity, cardiometabolic disease and the risk to develop AD in the offspring. Thus far only a handful of preclinical studies investigated the impact of maternal overnutrition/obesity on AD-like cognitive pathology. It was shown that MHFD led to impairment in memory in 2- and 12-month-old triple transgenic mouse model of $\mathrm{AD}$ (3xTgAD) offspring compared to control offspring (Martin et al., 2014). The memory impairments were accompanied by a 
significant increase in the number of hippocampal tau positive neurons. These findings may imply that MHFD can induce the onset and progression of AD later in life (Martin et al., 2014). In addition, it was demonstrated that the pathological $\mathrm{AD}$ marker, clearance of the $\beta$-amyloid peptide, was impaired in brains of MHFD offspring (Hawkes et al., 2015). Additionally, offspring born to MHFD Tg2576 mothers (i.e., the Tg2576 mouse model of AD which express the Swedish mutation in the human amyloid precursor protein) developed higher levels of hippocampal $\beta$-amyloid pathology compared to control offspring (Nizari et al., 2016).

\section{A LINK BETWEEN CENTRAL LIPIDS AND COGNITIVE FUNCTION?}

The brain is the most cholesterol rich organ in the body. The majority of central cholesterol accumulates during embryonic development and in the early postnatal period, while the metabolism of cholesterol in adulthood is characterized by a low turnover and minimal loss of cholesterol (Zhang and Liu, 2015). Brain cholesterol is proposed to be derived by de novo synthesis, since only small amounts of plasma cholesterol can transfer through the blood-brain barrier (BBB; Dietschy and Turley, 2001). Cholesterol supply to the central nervous system (CNS) is believed to be mediated by astrocytes and microglia, which predominantly secrete cholesterol and phospholipids together with apolipoprotein $\mathrm{E}(\mathrm{ApoE})$. ApoE, a protein involved in fats metabolism in the body, in turn serves as a ligand for these lipoproteins to affect the uptake of lipoproteins via the low-density lipoprotein receptor (LDLR) and the lipoprotein related protein (LRP; Lane-Donovan et al., 2014). Currently it is believed that ApoE-containing lipoproteins redistribute lipids and regulate cholesterol homeostasis within the brain (Mahley, 2016b). As cholesterol is essential for normal brain function including learning and memory, dysfunction in central cholesterol metabolism might lead to deficiencies that will induce structural and functional brain disorders such as $\mathrm{AD}$ (Kim et al., 2009a; Mahley, 2016a; Yamazaki et al., 2019). In this context, the expression of ApoE in the brain concomitant with LDLR function has been implicated. For example, one study demonstrated that overexpression of ApoE in the brain had beneficial effects on cognitive function as well as neural circuit function by enhancing the clearance of $A \beta$ (Cramer et al., 2012). Furthermore, LRP1 forebrain knockout mice show alterations in central lipid metabolism in brain regions important for cognitive function paralleled with impairments in memory (Liu et al., 2010). In addition, neuron-specific 2 (LPL) deficient mice display learning and memory deficits (Xian et al., 2009) and overexpression of brain LDL receptors reduces amyloid deposition and may represent a novel treatment for $\mathrm{AD}$ (Kim et al., 2009b). Thus, current evidence points to the fact that central cholesterol homeostasis is important for cognitive function. However, the link to peripheral cholesterol metabolism is not yet understood. More specifically, it remains unknown, by which mechanisms lipoproteins are produced in the brain and whether there may be a transport or a link to cholesterol precursors across the $\mathrm{BBB}$ thus connecting central and systemic lipid homeostasis?

\section{THE EFFECTS OF MATERNAL HFD EXPOSURE AND THE INCREASED RISK FOR CARDIO-METABOLIC DISEASE IN THE OFFSPRING}

In human epidemiological studies maternal BMI was positively correlated with cardiovascular events and premature death in the progeny (Reynolds et al., 2013). Maternal overnutrion/obesity was shown to induce a cardiometabolic phenotype (increased fat disposition, alterations in plasma metabolic markers, increased body weight, hyperinsulinemia, and fasting glucose levels) (Godfrey et al., 2017). In preclinical studies offspring born to over nourished mothers showed increased risk to develop cardiovascular pathology compared to their control counterparts (Samuelsson et al., 2008; Liang et al., 2009; Blackmore et al., 2014; Loche et al., 2018).

In order to try to investigate how maternal overnutrition/obesity influences the cardio-metabolic function of the offspring the body weight is not always a predictor of body composition. Some studies have shown that, despite similar body weights of the offspring of over nourished mothers and control offspring, elevated percentages of body fat can be detected (Buckley et al., 2005; Howie et al., 2009). These findings suggest that elevated body fat percentages may be more likely a result of reduced lean mass than an increase in fat mass per se. The pathophysiological processes underlying a cardio-metabolic state (obesity, diabetes, and cardiovascular dysfunction), cognitive decline and structural brain changes are most likely multifactorial. There are some evidence that inflammation (i) may be the cause of decline in cognitive processes in aging (Cornejo and von Bernhardi, 2016), (ii) is a risk factor for acceleration in cognitive decline (Stacey et al., 2015), and (iii) may be a cause for neurodegenerative disorders (Schain and Kreisl, 2017). Inflammation may cause alterations in brain structures such as reduced hippocampal and prefrontal volume (Bruehl et al., 2009), decrease in white matter (Kullmann et al., 2016), and reduction in total brain volume (Jefferson et al., 2007). In addition, inflammation processes were also associated with obesity and the metabolic syndrome (Guillemot-Legris and Muccioli, 2017). Taken together, these findings may suggest that one potential mechanism for explaining the exacerbation of cognitive decline observed in the offspring is alteration in pro-inflammatory markers in plasma and/or brain (Contu and Hawkes, 2017). Expression of brain pro-inflammatory markers such as TNF $\alpha$, IL1, and IL- 6 will in brain structures that predominantly underline memory, learning, and attentional processes, such as the hippocampus, prefrontal cortex, and the hypothalamus in different age stages of the offspring will enable the identifications of how longitudinal changes in inflammation markers might correlate with cognitive acceleration and/or cardiovascular dysfunction. C-reactive protein (CRP) is acting as an indicator for inflammation. In humans increased levels of 
circulation CRP was associated with reduced cognitive function and is used as a marker to predict future risk for stroke and ischemic attack (Kuo et al., 2005).

There is still very little known on the role of circulating lipoproteins and cholesterol on neuropathological disorders, such as aging and cognitive decline on the one hand and increased risk to develop cardiovascular disorders on the other hand. Enhancing our understanding on the role and function of lipoproteins and cholesterol in the brain and their transport to the brain, may have an enormous impact in this field. In addition, a potential target for treatment for age-related cognitive and cardio-metabolic disabilities.

\section{CONCLUSIONS AND FUTURE DIRECTIONS}

The epidemic of obesity is spreading fast through developed and developing countries. The latest projections from the WHO predict that 1 in 10 is obese (this is an average as in developed countries it is considerably higher). Obesity is a dangerous condition because it creates a permissive environment for many other health-related diseases, such as type 2 diabetes, hypertension and heart disease. Even more worrying are the facts that health problems not only affect the adult population, but also children (Ogden et al., 2014). Childhood obesity is of major concern because it will most likely be translated to higher rates of adult obesity and related comorbidities such as diabetes and cardiovascular disease (Freedman et al., 2007; Li et al., 2008; Pulgarón, 2013). Growing evidence in the past two decades has shown that maternal overnutrition and/or obesity has a long-term impact on offspring health, demonstrating that the in utero environment might be a key determinant of long-term health outcomes. However, that far epidemiological human studies cannot distinguish between the effect of overnutrition during pregnancy and postnatal nutrition (such as an obesogenic household). Many human studies investigating the long-term implications of developmental insults on the health of the offspring (such as famine or infection), can point to causality since the insults occur during a specific point in time, while the rest of the pregnancy and childhood is normal. In the case of maternal overnutrition in humans, there is chronic consumption of palatable food during pregnancy that continues into childhood and adolescence, thereby preventing a conclusive association between the metabolic phenotype of the adult offspring exposed to prenatal overnutrition. There are several other limitations to human observational studies due to methodological differences in the publish research that make conclusion difficult or impossible such as socio-economic factors, adjustment for maternal intelligence, inadequate reporting of

\section{REFERENCES}

Albuquerque, D., Manco, L., Nóbrega, C., and Padez, C. (2017). The contribution of genetics and environment to obesity. Br. Med. Bull. 123, 159-173. doi: $10.1093 / \mathrm{bmb} / \mathrm{ldx} 022$ nutrition evaluations (through self-reported questionnaires), sample selection, low power due to a small sample size, etc. Thus, the establishment of the effect of maternal overnutrition on the offspring can only be studied in isolation in animal models. The health consequences of in utero exposure to maternal overnutrition on future generations are thus an area of intense research.

Until now, there are a few intervention studies utilizing the maternal obesity animal model. Those studies employ dietary (for review Zambrano et al., 2010; Nathanielsz et al., 2013; Kang et al., 2014; Liu et al., 2020), physical exercise (Carter et al., 2012; Vega et al., 2015; Fernandez-Twinn et al., 2017)[151; 152; 153], or therapeutic/supplementation interventions during different developmental stages (Vickers et al., 2005; Sen and Simmons, 2010). Some of these studies report potential beneficial effects on metabolic and cognitive outcomes in the offspring (Vickers et al., 2005; Vickers and Sloboda, 2012). Different interventions, a combination of approaches and the time of intervention may act through different mechanisms, which limit the intervention strategies to prevent the detrimental effects of maternal obesity. To date there are only a handful of interventional human studies that try to mitigate the health adversities in the offspring due to maternal obesity (Han et al., 2012; Briley et al., 2014; Chiswick et al., 2015; Poston et al., 2015, 2017; Thangaratinam, 2015; Dodd et al., 2016).

Prevention of obesity in women of childbearing age and the prevention of obesity during childhood are essential to fight the global obesity epidemic. Further, it is of outmost importance to elucidate the specific mechanisms linking in utero exposure to an hyperphagic diet to the development of obesity as well as cardiovascular disorders. The latter is the number one cause of global mortality. Outcomes from animal studies have a potential to unravel novel and yet unknown mechanisms involved in the pathophysiology of cardio-metabolic disease and how they are linked to cognitive impairments. A deeper understanding of whether and how maternal overnutrition exerts noxious effects on the health of the offspring may allow the identification of new targets for future interventions against the development of obesity-related cardiovascular disorders and neuropathology.

\section{AUTHOR CONTRIBUTIONS}

DP-R conceptualized the project, conducted the systemic review of the literature, and wrote the manuscript.

\section{FUNDING}

This research was funded by the Swiss National Science Foundation (SNSF) [grant number 310030_189110].

Ashino, N. G., Saito, K. N., Souza, F. D., Nakutz, F. S., Roman, E. A., Velloso, L. A., et al. (2011). Maternal high-fat feeding through pregnancy and lactation predisposes mouse offspring to molecular insulin resistance and fatty liver. J. Nutr. Biochem. 23, 341-348. doi: 10.1016/j.jnutbio.2010. 12.011 
Ballard, C., Gauthier, S., Corbett, A., Brayne, C., Aarsland, D., and Jones, E. (2011). Alzheimer's disease. Lancet (Lond. Engl.) 377, 1019-1031.

Baranowski, B. J., Bott, K. N., and MacPherson, R. E. K. (2018). Evaluation of neuropathological effects of a high-fat high-sucrose diet in middle-aged male C57BL6/J mice. Physiol. Rep. 6:e13729. doi: 10.14814/phy2.13729

Barker, D. J. (2007). The origins of the developmental origins theory. J. Intern. Med. 261, 412-417. doi: 10.1111/j.1365-2796.2007.01809.x

Barker, D. J., Bull, A. R., Osmond, C., and Simmonds, S. J. (1990). Fetal and placental size and risk of hypertension in adult life. BMJ (Clin. Res. ed.) 301, 259-262. doi: 10.1136/bmj.301.6746.259

Bilbo, S. D., and Tsang, V. (2010). Enduring consequences of maternal obesity for brain inflammation and behavior of offspring. FASEB J. 24, 2104-2115. doi: 10.1096/fj.09-144014

Blackmore, H. L., Niu, Y., Fernandez-Twinn, D. S., Tarry-Adkins, J. L., Giussani, D. A., and Ozanne, S. E. (2014). Maternal diet-induced obesity programs cardiovascular dysfunction in adult male mouse offspring independent of current body weight. Endocrinology 155, 3970-3980. doi: 10.1210/en.20141383

Bliddal, M., Olsen, J., Støvring, H., Eriksen, H. L., Kesmodel, U. S., Sørensen, T. I., et al. (2014). Maternal pre-pregnancy BMI and intelligence quotient (IQ) in 5-year-old children: a cohort based study. PLoS One 9:e94498. doi: 10.1371/ journal.pone.0094498

Boksa, P. (2004). Animal models of obstetric complications in relation to schizophrenia. Brain Res. Brain Res. Rev. 45, 1-17. doi: 10.1016/j.brainresrev. 2004.01.001

Borenstein, A. R., Copenhaver, C. I., and Mortimer, J. A. (2006). Early-life risk factors for Alzheimer disease. Alzheimer Dis. Assoc. Disord. 20, 63-72. doi: 10.1097/01.wad.0000201854.62116.d7

Briley, A. L., Barr, S., Badger, S., Bell, R., Croker, H., Godfrey, K. M., et al. (2014). A complex intervention to improve pregnancy outcome in obese women; the UPBEAT randomised controlled trial. BMC Pregnancy Childbirth 14:74. doi: 10.1186/1471-2393-14-74

Brion, M. J., Zeegers, M., Jaddoe, V., Verhulst, F., Tiemeier, H., Lawlor, D. A., et al. (2011). Intrauterine effects of maternal prepregnancy overweight on child cognition and behavior in 2 cohorts. Pediatrics 127, e202-e211.

Bruehl, H., Wolf, O. T., Sweat, V., Tirsi, A., Richardson, S., and Convit, A. (2009). Modifiers of cognitive function and brain structure in middle-aged and elderly individuals with type 2 diabetes mellitus. Brain Res. 1280, 186-194. doi: 10. 1016/j.brainres.2009.05.032

Buckley, A. J., Keseru, B., Briody, J., Thompson, M., Ozanne, S. E., and Thompson, C. H. (2005). Altered body composition and metabolism in the male offspring of high fat-fed rats. Metabolism 54, 500-507. doi: 10.1016/j.metabol.2004.11.003

Buss, C., Entringer, S., Davis, E. P., Hobel, C. J., Swanson, J. M., Wadhwa, P. D., et al. (2012). Impaired executive function mediates the association between maternal pre-pregnancy body mass index and child ADHD symptoms. PLoS One 7:e37758. doi: 10.1371/journal.pone.0037758

Carter, L. G., Lewis, K. N., Wilkerson, D. C., Tobia, C. M., Ngo Tenlep, S. Y., Shridas, P., et al. (2012). Perinatal exercise improves glucose homeostasis in adult offspring. Am. J. Physiol. Endocrinol. Metab. 303, E1061-E1068.

Casas, M., Chatzi, L., Carsin, A. E., Amiano, P., Guxens, M., Kogevinas, M., et al. (2013). Maternal pre-pregnancy overweight and obesity, and child neuropsychological development: two Southern European birth cohort studies. Int. J. Epidemiol. 42, 506-517. doi: 10.1093/ije/dyt002

Chechi, K., Herzberg, G. R., and Cheema, S. K. (2010). Maternal dietary fat intake during gestation and lactation alters tissue fatty acid composition in the adult offspring of C57Bl/6 mice. Prostaglandins Leukot. Essent. Fatty Acids 83, 97-104. doi: 10.1016/j.plefa.2010.06.001

Chen, H., Simar, D., Lambert, K., Mercier, J., and Morris, M. J. (2008). Maternal and postnatal overnutrition differentially impact appetite regulators and fuel metabolism. Endocrinology 149, 5348-5356. doi: 10.1210/en.2008-0582

Chen, H., Simar, D., and Morris, M. J. (2009). Hypothalamic neuroendocrine circuitry is programmed by maternal obesity: interaction with postnatal nutritional environment. PLoS One 4:e6259. doi: 10.1371/journal.pone. 0006259

Chiswick, C., Reynolds, R. M., Denison, F., Drake, A. J., Forbes, S., Newby, D. E., et al. (2015). Effect of metformin on maternal and fetal outcomes in obese pregnant women (EMPOWaR): a randomised, double-blind, placebocontrolled trial. Lancet Diabetes Endocrinol. 3, 778-786. doi: 10.1016/s22138587(15)00219-3

Contu, L., and Hawkes, C. A. (2017). A review of the impact of maternal obesity on the cognitive function and mental health of the offspring. Int. J. Mol. Sci. 18:1093. doi: $10.3390 / \mathrm{ijms} 18051093$

Cordner, Z. A., and Tamashiro, K. L. (2015). Effects of high-fat diet exposure on learning \& memory. Physiol. Behav. 152, 363-371. doi: 10.1016/j.physbeh.2015. 06.008

Cornejo, F., and von Bernhardi, R. (2016). Age-Dependent changes in the activation and regulation of microglia. Adv. Exp. Med. Biol. 949, 205-226. doi: 10.1007/978-3-319-40764-7_10

Cramer, P. E., Cirrito, J. R., Wesson, D. W., Lee, C. Y., Karlo, J. C., Zinn, A. E., et al. (2012). ApoE-directed therapeutics rapidly clear beta-amyloid and reverse deficits in AD mouse models. Science (New York, N.Y.) 335, 1503-1506.

Dietschy, J. M., and Turley, S. D. (2001). Cholesterol metabolism in the brain. Curr. Opin. Lipidol. 12, 105-112.

Dodd, J. M., Newman, A., Moran, L. J., Deussen, A. R., Grivell, R. M., Yelland, L. N., et al. (2016). The effect of antenatal dietary and lifestyle advice for women who are overweight or obese on emotional well-being: the LIMIT randomized trial. Acta Obstet. Gynecol. Scand. 95, 309-318. doi: 10.1111/aogs.12832

Dunn, G. A., and Bale, T. L. (2009). Maternal high-fat diet promotes body length increases and insulin insensitivity in second-generation mice. Endocrinology 150, 4999-5009. doi: 10.1210/en.2009-0500

Dunn, G. A., and Bale, T. L. (2011). Maternal high-fat diet effects on thirdgeneration female body size via the paternal lineage. Endocrinology 152, 22282236. doi: 10.1210/en.2010-1461

Dunn, G. A., Morgan, C. P., and Bale, T. L. (2011). Sex-specificity in transgenerational epigenetic programming. Horm. Behav. 59, 290-295. doi: 10.1016/j.yhbeh.2010.05.004

Elahi, M. M., Cagampang, F. R., Mukhtar, D., Anthony, F. W., Ohri, S. K., and Hanson, M. A. (2009). Long-term maternal high-fat feeding from weaning through pregnancy and lactation predisposes offspring to hypertension, raised plasma lipids and fatty liver in mice. Br. J. Nutr. 102, 514-519. doi: 10.1017/ s000711450820749x

Fernandez-Twinn, D. S., Gascoin, G., Musial, B., Carr, S., Duque-Guimaraes, D., Blackmore, H. L., et al. (2017). Exercise rescues obese mothers' insulin sensitivity, placental hypoxia and male offspring insulin sensitivity. Sci. Rep. 7:44650.

Freedman, D. S., Mei, Z., Srinivasan, S. R., Berenson, G. S., and Dietz, W. H. (2007). Cardiovascular risk factors and excess adiposity among overweight children and adolescents: the bogalusa heart study. J. Pediatr. 150, 12-17.e2.

Gage, S. H., Lawlor, D. A., Tilling, K., and Fraser, A. (2013). Associations of maternal weight gain in pregnancy with offspring cognition in childhood and adolescence: findings from the Avon Longitudinal Study of Parents and Children. Am. J. Epidemiol. 177, 402-410. doi: 10.1093/aje/kws239

Gerstein, H., Hullinger, R., Lindstrom, M. J., and Burger, C. (2013). A behavioral paradigm to evaluate hippocampal performance in aged rodents for pharmacological and genetic target validation. PLoS One 8:e62360. doi: 10.1371/journal.pone.0062360

Ghosh, P., Bitsanis, D., Ghebremeskel, K., Crawford, M. A., and Poston, L. (2001). Abnormal aortic fatty acid composition and small artery function in offspring of rats fed a high fat diet in pregnancy. J. Physiol. 533, 815-822. doi: 10.1111/j. 1469-7793.2001.00815.x

Godfrey, K. M., Reynolds, R. M., Prescott, S. L., Nyirenda, M., Jaddoe, V. W., Eriksson, J. G., et al. (2017). Influence of maternal obesity on the long-term health of offspring. Lancet Diabetes Endocrinol. 5, 53-64.

Graf, A. E., Lallier, S. W., Waidyaratne, G., Thompson, M. D., Tipple, T. E., Hester, M. E., et al. (2016). Maternal high fat diet exposure is associated with increased hepcidin levels, decreased myelination, and neurobehavioral changes in male offspring. Brain Behav. Immun. 58, 369-378. doi: 10.1016/j.bbi.2016. 08.005

Grant, W. B. (1999). Dietary links to Alzheimer's disease: 1999 update. J. Alzheimers Dis. JAD 1, 197-201. doi: 10.3233/jad-1999-14-501 
Gregersen, S., Dyrskog, S. E., Storlien, L. H., and Hermansen, K. (2005). Comparison of a high saturated fat diet with a high carbohydrate diet during pregnancy and lactation: effects on insulin sensitivity in offspring of rats. Metabolism 54, 1316-1322. doi: 10.1016/j.metabol.2005.04.020

Gregor, L., Remington, P. L., Lindberg, S., and Ehrenthal, D. (2016). Prevalence of Pre-pregnancy Obesity, 2011-2014. WMJ 115, 228-232.

Gregorio, B. M., Souza-Mello, V., Carvalho, J. J., Mandarim-de-Lacerda, C. A., and Aguila, M. B. (2010). Maternal high-fat intake predisposes nonalcoholic fatty liver disease in C57BL/6 offspring. Am. J. Obstetr. Gynecol. 203, e1-e8.

Guillemot-Legris, O., and Muccioli, G. G. (2017). Obesity-Induced neuroinflammation: beyond the hypothalamus. Trends Neurosci. 40, 237-253. doi: 10.1016/j.tins.2017.02.005

Gustafson, D. R. (2012). Adiposity and cognitive decline: underlying mechanisms. J. Alzheimers Dis. JAD 30(Suppl. 2), S97-S112.

Han, S., Middleton, P., and Crowther, C. A. (2012). Exercise for pregnant women for preventing gestational diabetes mellitus. Cochrane Database Syst. Rev. 7:Cd009021.

Hardy, J. A., and Higgins, G. A. J. S. (1992). Alzheimer's disease: the amyloid cascade hypothesis. Science 256, 184-186.

Hawkes, C. A., Gentleman, S. M., Nicoll, J. A., and Carare, R. O. (2015). Prenatal high-fat diet alters the cerebrovasculature and clearance of $\beta$-amyloid in adult offspring. J. Pathol. 235, 619-631. doi: 10.1002/path.4468

Heslehurst, N., Rankin, J., Wilkinson, J. R., and Summerbell, C. D. (2010). A nationally representative study of maternal obesity in England, UK: trends in incidence and demographic inequalities in 619323 births, 1989-2007. Int. J. Obes. (2005) 34, 420-428. doi: 10.1038/ijo.2009.250

Hinkle, S. N., Schieve, L. A., Stein, A. D., Swan, D. W., Ramakrishnan, U., and Sharma, A. J. (2012). Associations between maternal prepregnancy body mass index and child neurodevelopment at 2 years of age. Int. J. Obes. (2005) 36, 1312-1319. doi: 10.1038/ijo.2012.143

Hooijmans, C. R., and Kiliaan, A. J. (2008). Fatty acids, lipid metabolism and Alzheimer pathology. Eur. J. Pharmacol. 585, 176-196. doi: 10.1016/j.ejphar. 2007.11.081

Howie, G. J., Sloboda, D. M., Kamal, T., and Vickers, M. H. (2009). Maternal nutritional history predicts obesity in adult offspring independent of postnatal diet. J. Physiol. 587, 905-915. doi: 10.1113/jphysiol.2008.163477

Hruby, A., and Hu, F. B. (2015). The epidemiology of obesity: a big picture. Pharmacoeconomics 33, 673-689. doi: 10.1007/s40273-014-0243-x

Huang, L., Yu, X., Keim, S., Li, L., Zhang, L., and Zhang, J. (2014). Maternal prepregnancy obesity and child neurodevelopment in the Collaborative Perinatal Project. Int. J. Epidemiol. 43, 783-792. doi: 10.1093/ije/dyu030

Huda, S. S., Brodie, L. E., and Sattar, N. (2010). Obesity in pregnancy: prevalence and metabolic consequences. Semin. Fetal Neonatal Med. 15, 70-76. doi: 10. 1016/j.siny.2009.09.006

Ishii, T. (1966). Distribution of Alzheimer's neurofibrillary changes in the brain stem and hypothalamus of senile dementia. Acta Neuropathol. 6, 181-187. doi: $10.1007 / \mathrm{bf} 00686763$

Janthakhin, Y., Rincel, M., Costa, A. M., Darnaudéry, M., and Ferreira, G. (2017). Maternal high-fat diet leads to hippocampal and amygdala dendritic remodeling in adult male offspring. Psychoneuroendocrinology 83, 49-57. doi: 10.1016/j.psyneuen.2017.05.003

Jefferson, A. L., Massaro, J. M., Wolf, P. A., Seshadri, S., Au, R., Vasan, R. S., et al. (2007). Inflammatory biomarkers are associated with total brain volume: the Framingham Heart Study. Neurology 68, 1032-1038. doi: 10.1212/01.wnl. 0000257815.20548.df

Jenabi, E., Bashirian, S., Khazaei, S., and Basiri, Z. (2019). The maternal prepregnancy body mass index and the risk of attention deficit hyperactivity disorder among children and adolescents: a systematic review and metaanalysis. Korean J. Pediatr. 62, 374-379. doi: 10.3345/kjp.2019.00185

Kang, S. S., Kurti, A., Fair, D. A., and Fryer, J. D. (2014). Dietary intervention rescues maternal obesity induced behavior deficits and neuroinflammation in offspring. J. Neuroinflammation 11:156.

Keim, S. A., and Pruitt, N. T. (2012). Gestational weight gain and child cognitive development. Int. J. Epidemiol. 41, 414-422. doi: 10.1093/ije/dyr229

Khan, I. Y., Dekou, V., Douglas, G., Jensen, R., Hanson, M. A., Poston, L., et al. (2005). A high-fat diet during rat pregnancy or suckling induces cardiovascular dysfunction in adult offspring. Am. J. Physiol. Regul. Integr. Comp. Physiol. 288, R127-R133.
Killin, L. O., Starr, J. M. I, Shiue, J., and Russ, T. C. (2016). Environmental risk factors for dementia: a systematic review. BMC Geriatr. 16:175. doi: 10.1186/ s12877-016-0342-y

Kim, J., Basak, J. M., and Holtzman, D. M. (2009a). The role of apolipoprotein E in Alzheimer's disease. Neuron 63, 287-303.

Kim, J., Castellano, J. M., Jiang, H., Basak, J. M., Parsadanian, M., Pham, V., et al. (2009b). Overexpression of low-density lipoprotein receptor in the brain markedly inhibits amyloid deposition and increases extracellular A beta clearance. Neuron 64, 632-644. doi: 10.1016/j.neuron.2009.11.013

Kim, T. W., and Park, H. S. (2018). Physical exercise improves cognitive function by enhancing hippocampal neurogenesis and inhibiting apoptosis in male offspring born to obese mother. Behav. Brain Res. 347, 360-367. doi: 10.1016/j. bbr.2018.03.018

Kominiarek, M. A., and Chauhan, S. P. (2016). Obesity before, during, and after pregnancy: a review and comparison of five national guidelines. Am. J. Perinatol. 33, 433-441. doi: 10.1055/s-0035-1567856

Kominiarek, M. A., and Peaceman, A. M. (2017). Gestational weight gain. Am. J. Obstetr. Gynecol. 217, 642-651.

Kong, L., Chen, X., Gissler, M., and Lavebratt, C. (2020). Relationship of prenatal maternal obesity and diabetes to offspring neurodevelopmental and psychiatric disorders: a narrative review. Int. J. Obes. 44, 1981-2000. doi: 10.1038/s41366020-0609-4

Kral, T. V., and Rauh, E. M. (2010). Eating behaviors of children in the context of their family environment. Physiol. Behav. 100, 567-573. doi: 10.1016/j.physbeh. 2010.04.031

Kullmann, S., Callaghan, M. F., Heni, M., Weiskopf, N., Scheffler, K., Haring, H. U., et al. (2016). Specific white matter tissue microstructure changes associated with obesity. NeuroImage 125, 36-44. doi: 10.1016/j.neuroimage.2015.10.006

Kuo, H. K., Yen, C. J., Chang, C. H., Kuo, C. K., Chen, J. H., and Sorond, F. (2005). Relation of C-reactive protein to stroke, cognitive disorders, and depression in the general population: systematic review and meta-analysis. Lancet Neurol. 4, 371-380. doi: 10.1016/s1474-4422(05)70099-5

Lahiri, D. K., Zawia, N. H., Greig, N. H., Sambamurti, K., and Maloney, B. (2008). Early-life events may trigger biochemical pathways for Alzheimer's disease: the "LEARn" model. Biogerontology 9, 375-379. doi: 10.1007/s10522-008-9162-6

Laitinen, M. H., Ngandu, T., Rovio, S., Helkala, E. L., Uusitalo, U., Viitanen, M., et al. (2006). Fat intake at midlife and risk of dementia and Alzheimer's disease: a population-based study. Dement. Geriatr. Cogn. Disord. 22, 99-107. doi: $10.1159 / 000093478$

Lane-Donovan, C. E., Philips, G. T., and Herz, J. (2014). More than cholesterol transporters: lipoprotein receptors in CNS function and neurodegeneration. Neuron 83, 771-787. doi: 10.1016/j.neuron.2014.08.005

Lawlor, D. A., Smith, G. D., O'Callaghan, M., Alati, R., Mamun, A. A., Williams, G. M., et al. (2007). Epidemiologic evidence for the fetal overnutrition hypothesis: findings from the mater-university study of pregnancy and its outcomes. Am. J. Epidemiol. 165, 418-424. doi: 10.1093/aje/kwk030

Lépinay, A. L., Larrieu, T., Joffre, C., Acar, N., Gárate, I., Castanon, N., et al. (2015). Perinatal high-fat diet increases hippocampal vulnerability to the adverse effects of subsequent high-fat feeding. Psychoneuroendocrinology 53, 82-93. doi: 10. 1016/j.psyneuen.2014.12.008

Lewis, A. R., Singh, S., and Youssef, F. F. (2019). Cafeteria-diet induced obesity results in impaired cognitive functioning in a rodent model. Heliyon 5:e1412. doi: 10.1016/j.heliyon.2019.e01412

Li, L., Lagerberg, T., Chang, Z., Cortese, S., Rosenqvist, M. A., Almqvist, C., et al. (2020). Maternal pre-pregnancy overweight/obesity and the risk of attentiondeficit/hyperactivity disorder in offspring: a systematic review, meta-analysis and quasi-experimental family-based study. Int. J. Epidemiol. 49, 857-875. doi: 10.1093/ije/dyaa040

Li, M., Fallin, M. D., Riley, A., Landa, R., Walker, S. O., Silverstein, M., et al. (2016). The association of maternal obesity and diabetes with autism and other developmental disabilities. Pediatrics 137:e20152206. doi: 10.1542/peds.20152206

Li, Y., Dai, Q., Jackson, J. C., and Zhang, J. (2008). Overweight is associated with decreased cognitive functioning among school-age children and adolescents. Obesity (Silver Spring, Md.) 16, 1809-1815. doi: 10.1038/oby.20 08.296

Liang, C., Oest, M. E., and Prater, M. R. (2009). Intrauterine exposure to high saturated fat diet elevates risk of adult-onset chronic diseases in C57BL/6 mice. 
Birth Defects Res. B Dev. Reprod. Toxicol. 86, 377-384. doi: 10.1002/bdrb. 20206

Lindberg, S., Anderson, C., Pillai, P., Tandias, A., Arndt, B., and Hanrahan, L. (2016). Prevalence and predictors of unhealthy weight gain in pregnancy. WMJ $115,233-237$.

Liu, Q., Trotter, J., Zhang, J., Peters, M. M., Cheng, H., Bao, J., et al. (2010). Neuronal LRP1 knockout in adult mice leads to impaired brain lipid metabolism and progressive, age-dependent synapse loss and neurodegeneration. J. Neurosci. 30, 17068-17078. doi: 10.1523/jneurosci. 4067-10.2010

Liu, X., Li, X., Xia, B., Jin, X., Zeng, Z., Yan, S., et al. (2020). High-Fiber diet restores maternal obesity-induced cognitive and social behavioral deficits in offspring via regulating gut microbiota-metabolites-brain axis. bioRxiv [preprint]. doi: $10.1101 / 2020.07 .16 .206714$

Lloret, A., Monllor, P., Esteve, D., Cervera-Ferri, A., and Lloret, A. (2019). Obesity as a risk factor for Alzheimer's disease: implication of leptin and glutamate. 13:508

Loche, E., Blackmore, H. L., Carpenter, A. A., Beeson, J. H., Pinnock, A., Ashmore, T. J., et al. (2018). Maternal diet-induced obesity programmes cardiac dysfunction in male mice independently of post-weaning diet. Cardiovasc. Res. 114, 1372-1384. doi: $10.1093 / \mathrm{cvr} / \mathrm{cvy} 082$

Luchsinger, J. A., Tang, M. X., Shea, S., and Mayeux, R. (2002). Caloric intake and the risk of Alzheimer disease. Arch. Neurol. 59, 1258-1263. doi: 10.1001/ archneur.59.8.1258

Mahley, R. W. (2016a). Apolipoprotein E: from cardiovascular disease to neurodegenerative disorders. J. Mol. Med. (Berlin, Germany) 94, 739-746. doi: $10.1007 / \mathrm{s} 00109-016-1427-\mathrm{y}$

Mahley, R. W. (2016b). Central nervous system lipoproteins: ApoE and regulation of cholesterol metabolism. Arterioscler. Thromb. Vasc. Biol. 36, 1305-1315. doi: $10.1161 /$ atvbaha.116.307023

Martin, S. A., Jameson, C. H., Allan, S. M., and Lawrence, C. B. (2014). Maternal high-fat diet worsens memory deficits in the triple-transgenic (3xTgAD) mouse model of Alzheimer's disease. PLoS One 9:e99226. doi: 10.1371/journal.pone. 0099226

McAninch, D., Bianco-Miotto, T., Gatford, K. L., Leemaqz, S. Y., Andraweera, P. H., Garrett, A., et al. (2020). The metabolic syndrome in pregnancy and its association with child telomere length. Diabetologia 63, 2140-2149. doi: 10.1007/s00125-020-05242-0

McMillen, I. C., Adam, C. L., and Muhlhausler, B. S. (2005). Early origins of obesity: programming the appetite regulatory system. J. Physiol. 565, 9-17. doi: 10.1113/jphysiol.2004.081992

Miller, A. A., and Spencer, S. J. (2014). Obesity and neuroinflammation: a pathway to cognitive impairment. Brain Behav. Immun. 42, 10-21. doi: 10.1016/j.bbi. 2014.04.001

Miller, D. B., and O'Callaghan, J. P. (2008). Do early-life insults contribute to the late-life development of Parkinson and Alzheimer diseases? Metabolism 57(Suppl. 2), S44-S49.

Moreton, E., Baron, P., Tiplady, S., McCall, S., Clifford, B., Langley-Evans, S. C., et al. (2019). Impact of early exposure to a cafeteria diet on prefrontal cortex monoamines and novel object recognition in adolescent rats. Behav. Brain Res. 363, 191-198. doi: 10.1016/j.bbr.2019.02.003

Morris, M. J., and Chen, H. (2009). Established maternal obesity in the rat reprograms hypothalamic appetite regulators and leptin signaling at birth. Int. J. Obes. (2005) 33, 115-122. doi: 10.1038/ijo.2008.213

Naef, L., Moquin, L., Dal Bo, G., Giros, B., Gratton, A., and Walker, C. D. (2011). Maternal high-fat intake alters presynaptic regulation of dopamine in the nucleus accumbens and increases motivation for fat rewards in the offspring. Neuroscience 176, 225-236. doi: 10.1016/j.neuroscience.2010.12.037

Naef, L., Srivastava, L., Gratton, A., Hendrickson, H., Owens, S. M., and Walker, C. D. (2008). Maternal high fat diet during the perinatal period alters mesocorticolimbic dopamine in the adult rat offspring: reduction in the behavioral responses to repeated amphetamine administration. Psychopharmacology 197, 83-94. doi: 10.1007/s00213-007-1008-4

Nathanielsz, P. W., Ford, S. P., Long, N. M., Vega, C. C., Reyes-Castro, L. A., and Zambrano, E. (2013). Interventions to prevent adverse fetal programming due to maternal obesity during pregnancy. Nutr. Rev. 71(Suppl. 1), S78-S87.
Neggers, Y. H., Goldenberg, R. L., Ramey, S. L., and Cliver, S. P. (2003). Maternal prepregnancy body mass index and psychomotor development in children. Acta Obstet. Gynecol. Scand. 82, 235-240. doi: 10.1034/j.1600-0412.2003.00090.x

Ng, M., Fleming, T., Robinson, M., Thomson, B., Graetz, N., Margono, C., et al. (2014). Global, regional, and national prevalence of overweight and obesity in children and adults during 1980-2013: a systematic analysis for the Global Burden of Disease Study 2013. Lancet (London, England) 384, 766-781.

Niculescu, M. D., and Lupu, D. S. (2009). High fat diet-induced maternal obesity alters fetal hippocampal development. Int. J. Dev. Neurosci. 27, 627-633. doi: 10.1016/j.ijdevneu.2009.08.005

Nizari, S., Carare, R. O., and Hawkes, C. A. (2016). Increased A $\beta$ pathology in aged Tg2576 mice born to mothers fed a high fat diet. Sci. Rep. 6:21981.

Ogden, C. L., Carroll, M. D., Kit, B. K., and Flegal, K. M. (2014). Prevalence of childhood and adult obesity in the United States, 2011-2012. JAMA 311, 806-814. doi: 10.1001/jama.2014.732

Oken, E., Taveras, E. M., Kleinman, K. P., Rich-Edwards, J. W., and Gillman, M. W. (2007). Gestational weight gain and child adiposity at age 3 years. Am. J. Obstet. Gynecol. 196, e1-e8.

Page, K. C., Jones, E. K., and Anday, E. K. (2014). Maternal and postweaning highfat diets disturb hippocampal gene expression, learning, and memory function. Am. J. Physiol. Regul. Integr. Comp. Physiol. 306, R527-R537.

Panza, F., Solfrizzi, V., Colacicco, A., D’introno, A., Capurso, C., Torres, F., et al. (2004). Mediterranean diet and cognitive decline. Public Health Nutr. 7 , 959-963.

Peleg-Raibstein, D., Luca, E., and Wolfrum, C. (2012). Maternal high-fat diet in mice programs emotional behavior in adulthood. Behav. Brain Res. 233, 398-404. doi: 10.1016/j.bbr.2012.05.027

Peleg-Raibstein, D., Sarker, G., Litwan, K., Kramer, S. D., Ametamey, S. M., Schibli, R., et al. (2016). Enhanced sensitivity to drugs of abuse and palatable foods following maternal overnutrition. Transl. Psychiatry 6:e911. doi: 10.1038/tp. 2016.176

Poston, L., Bell, R., Briley, A. L., Godfrey, K. M., Nelson, S. M., Oteng-Ntim, E., et al. (2017). "Improving pregnancy outcome in obese women: the UK Pregnancies Better Eating and Activity randomised controlled Trial," in Programme Grants for Applied Research, No. 5.10, (Southampton, UK: NIHR Journals Library).

Poston, L., Bell, R., Croker, H., Flynn, A. C., Godfrey, K. M., Goff, L., et al. (2015). Effect of a behavioural intervention in obese pregnant women (the UPBEAT study): a multicentre, randomised controlled trial. Lancet Diabetes Endocrinol. 3, 767-777. doi: 10.1016/s2213-8587(15)00227-2

Pugh, S. J., Richardson, G. A., Hutcheon, J. A., Himes, K. P., Brooks, M. M., Day, N. L., et al. (2015). Maternal obesity and excessive gestational weight gain are associated with components of child cognition. J. Nutr. 145, 2562-2569. doi: $10.3945 /$ jn.115.215525

Pulgarón, E. R. (2013). Childhood obesity: a review of increased risk for physical and psychological comorbidities. Clin. Ther. 35, A18-A32.

Reynolds, R. M., Allan, K. M., Raja, E. A., Bhattacharya, S., McNeill, G., Hannaford, P. C., et al. (2013). Maternal obesity during pregnancy and premature mortality from cardiovascular event in adult offspring: follow-up of 1323275 person years. BMJ Clin. Res. ed. 347:f4539. doi: 10.1136/bmj.f4539

Ribeiro, A., Batista, T. H., Veronesi, V. B., Giusti-Paiva, A., and Vilela, F. C. (2018). Cafeteria diet during the gestation period programs developmental and behavioral courses in the offspring. Int. J. Dev. Neurosci. 68, 45-52. doi: 10.1016/j.ijdevneu.2018.05.001

Robb, J. L., Messa, I., Lui, E., Yeung, D., Thacker, J., Satvat, E., et al. (2017). A maternal diet high in saturated fat impairs offspring hippocampal function in a sex-specific manner. Behav. Brain Res. 326, 187-199. doi: 10.1016/j.bbr.2017. 02.049

Robinson, S. L., Ghassabian, A., Sundaram, R., Trinh, M.-H., Lin, T.-C., Bell, E. M., et al. (2020). Parental weight status and offspring behavioral problems and psychiatric symptoms. J. Pediatr. 220, 227-236.e1.

Rodriguez, A. (2010). Maternal pre-pregnancy obesity and risk for inattention and negative emotionality in children. J. Child Psychol. Psychiatry 51, 134-143. doi: 10.1111/j.1469-7610.2009.02133.x

Rodriguez, A., Miettunen, J., Henriksen, T. B., Olsen, J., Obel, C., Taanila, A., et al. (2008). Maternal adiposity prior to pregnancy is associated with ADHD symptoms in offspring: evidence from three prospective pregnancy cohorts. Int. J. Obes. (2005) 32, 550-557. doi: 10.1038/sj.ijo.0803741 
Samuelsson, A. M., Matthews, P. A., Argenton, M., Christie, M. R., McConnell, J. M., Jansen, E. H., et al. (2008). Diet-induced obesity in female mice leads to offspring hyperphagia, adiposity, hypertension, and insulin resistance: a novel murine model of developmental programming. Hypertension 51, 383-392. doi: 10.1161/hypertensionaha.107.101477

Saper, C. B., and German, D. C. (1987). Hypothalamic pathology in Alzheimer's disease. Neurosci. Lett. 74, 364-370.

Sarker, G., Berrens, R., von Arx, J., Pelczar, P., Reik, W., Wolfrum, C., et al. (2018). Transgenerational transmission of hedonic behaviors and metabolic phenotypes induced by maternal overnutrition. Transl. Psychiatry 8:195.

Sarker, G., Litwan, K., Kastli, R., and Peleg-Raibstein, D. (2019a). Maternal overnutrition during critical developmental periods leads to different health adversities in the offspring: relevance of obesity, addiction and schizophrenia. Sci. Rep. 9:17322.

Sarker, G., and Peleg-Raibstein, D. (2018). Maternal overnutrition induces longterm cognitive deficits across several generations. Nutrients 11:7. doi: 10.3390/ nu11010007

Sarker, G., Sun, W., Rosenkranz, D., Pelczar, P., Opitz, L., Efthymiou, V., et al. (2019b). Maternal overnutrition programs hedonic and metabolic phenotypes across generations through sperm tsRNAs. Proc. Natl. Acad. Sci. U.S.A. 116, 10547-10556. doi: 10.1073/pnas.1820810116

Schain, M., and Kreisl, W. C. (2017). Neuroinflammation in neurodegenerative disorders-a review. Curr. Neurol. Neurosc. Rep. 17:25.

Sellbom, K. S., and Gunstad, J. (2012). Cognitive function and decline in obesity. J. Alzheimers Dis. JAD 30(Suppl. 2), S89-S95.

Sen, S., and Simmons, R. A. (2010). Maternal antioxidant supplementation prevents adiposity in the offspring of Western diet-fed rats. Diabetes 59, 30583065. doi: 10.2337/db10-0301

Sheikh, A. B., Nasrullah, A., Haq, S., Akhtar, A., Ghazanfar, H., Nasir, A., et al. (2017). The interplay of genetics and environmental factors in the development of obesity. Cureus 9:e1435.

Siemelink, M., Verhoef, A., Dormans, J. A., Span, P. N., and Piersma, A. H. (2002). Dietary fatty acid composition during pregnancy and lactation in the rat programs growth and glucose metabolism in the offspring. Diabetologia 45, 1397-1403. doi: 10.1007/s00125-002-0918-2

Simar, D., Chen, H., Lambert, K., Mercier, J., and Morris, M. J. (2011). Interaction between maternal obesity and post-natal over-nutrition on skeletal muscle metabolism. Nutr. Metab. Cardiovasc. Dis. 3:3.

Stacey, D., Ciobanu, L. G., and Baune, B. T. (2015). A systematic review on the association between inflammatory genes and cognitive decline in nondemented elderly individuals. Eur. Neuropsychopharmacol. 27, 568-588. doi: 10.1016/j.euroneuro.2015.12.017

Strakovsky, R. S., Zhang, X., Zhou, D., and Pan, Y. X. (2011). Gestational high fat diet programs hepatic phosphoenolpyruvate carboxykinase gene expression and histone modification in neonatal offspring rats. J. Physiol. 589, 2707-2717. doi: 10.1113/jphysiol.2010.203950

Stranahan, A. M., and Mattson, M. P. (2008). Impact of energy intake and expenditure on neuronal plasticity. Neuromolecular Med. 10, 209-218. doi: 10.1007/s12017-008-8043-0

Stranahan, A. M., Norman, E. D., Lee, K., Cutler, R. G., Telljohann, R. S., Egan, J. M., et al. (2008). Diet-induced insulin resistance impairs hippocampal synaptic plasticity and cognition in middle-aged rats. Hippocampus 18, 10851088. doi: 10.1002/hipo. 20470

Tamashiro, K. L., Terrillion, C. E., Hyun, J., Koenig, J. I., and Moran, T. H. (2009). Prenatal stress or high-fat diet increases susceptibility to diet-induced obesity in rat offspring. Diabetes 58, 1116-1125. doi: 10.2337/db08-1129

Tanda, R., Salsberry, P. J., Reagan, P. B., and Fang, M. Z. (2013). The impact of prepregnancy obesity on children's cognitive test scores. Matern. Child Health J. 17, 222-229. doi: 10.1007/s10995-012-0964-4

Thangaratinam, S. (2015). Diet and lifestyle interventions for obese pregnant women. Lancet Diabetes Endocrinol. 3, 748-749. doi: 10.1016/s2213-8587(15) 00253-3

Tolppanen, A. M., Ahonen, R., Koponen, M., Lavikainen, P., Purhonen, M., Taipale, H., et al. (2016). Month and season of birth as a risk factor for alzheimer's disease: a nationwide nested case-control study. J. Prev. Med. Public Health 49, 134-138. doi: 10.3961/jpmph.16.018

Tozuka, Y., Kumon, M., Wada, E., Onodera, M., Mochizuki, H., and Wada, K. (2010). Maternal obesity impairs hippocampal BDNF production and spatial learning performance in young mouse offspring. Neurochem. Int. 57, 235-247. doi: 10.1016/j.neuint.2010.05.015

Tozuka, Y., Wada, E., and Wada, K. (2009). Diet-induced obesity in female mice leads to peroxidized lipid accumulations and impairment of hippocampal neurogenesis during the early life of their offspring. FASEB J. 23, 1920-1934. doi: 10.1096/fj.08-124784

Van Lieshout, R. J. (2013). Role of maternal adiposity prior to and during pregnancy in cognitive and psychiatric problems in offspring. Nutr. Rev. 71(Suppl. 1), S95-S101.

Van Lieshout, R. J., Taylor, V. H., and Boyle, M. H. (2011). Pre-pregnancy and pregnancy obesity and neurodevelopmental outcomes in offspring: a systematic review. Obes. Rev. 12, e548-e559.

Vega, C. C., Reyes-Castro, L. A., Bautista, C. J., Larrea, F., Nathanielsz, P. W., and Zambrano, E. (2015). Exercise in obese female rats has beneficial effects on maternal and male and female offspring metabolism. Int. J. Obes. 39, 712-719. doi: 10.1038/ijo.2013.150

Vickers, M. H., Gluckman, P. D., Coveny, A. H., Hofman, P. L., Cutfield, W. S., Gertler, A., et al. (2005). Neonatal leptin treatment reverses developmental programming. Endocrinology 146, 4211-4216. doi: 10.1210/en.20050581

Vickers, M. H., and Sloboda, D. M. (2012). Strategies for reversing the effects of metabolic disorders induced as a consequence of developmental programming. Front. Physiol. 3:242. doi: 10.3389/fphys.2012. 00242

Vogt, M. C., Paeger, L., Hess, S., Steculorum, S. M., Awazawa, M., Hampel, B., et al. (2014). Neonatal insulin action impairs hypothalamic neurocircuit formation in response to maternal high-fat feeding. Cell 156, 495-509. doi: 10.1016/j.cell. 2014.01.008

Vorhees, C. V., and Williams, M. T. (2014). Assessing spatial learning and memory in rodents. ILAR J. 55, 310-332. doi: 10.1093/ilar/ilu013

Vucetic, Z., Kimmel, J., Totoki, K., Hollenbeck, E., and Reyes, T. M. (2010). Maternal high-fat diet alters methylation and gene expression of dopamine and opioid-related genes. Endocrinology 151, 4756-4764. doi: 10.1210/en.20100505

Wahlig, J. L., Bales, E. S., Jackman, M. R., Johnson, G. C., McManaman, J. L., and Maclean, P. S. (2011). Impact of high-fat diet and obesity on energy balance and fuel utilization during the metabolic challenge of lactation. Obesity (Silver Spring, Md.) 30:196.

Whitaker, R. C. (2004). Predicting preschooler obesity at birth: the role of maternal obesity in early pregnancy. Pediatrics 114, e29-e36.

White, C. L., Pistell, P. J., Purpera, M. N., Gupta, S., Fernandez-Kim, S. O., Hise, T. L., et al. (2009). Effects of high fat diet on Morris maze performance, oxidative stress, and inflammation in rats: contributions of maternal diet. Neurobiol. Dis. 35, 3-13. doi: 10.1016/j.nbd.2009.04.002

WHO (2020). Obesity and Overweight Fact Sheet. Geneva: World Health Organization (WHO).

Wolfrum, C., and Peleg-Raibstein, D. (2018). Maternal overnutrition leads to cognitive and neurochemical abnormalities in C57BL/6 mice. Nutr. Neurosci. 22, 688-699. doi: 10.1080/1028415x.2018.1432096

Wraw, C. I, Deary, J., Der, G., and Gale, C. R. (2018). Maternal and offspring intelligence in relation to BMI across childhood and adolescence. Int. J. Obes. 42, 1610-1620. doi: 10.1038/s41366-018-0009-1

Wright, T. M., King, M. V., Davey, W. G., Langley-Evans, S. C., and Voigt, J. P. (2014). Impact of cafeteria feeding during lactation in the rat on novel object discrimination in the offspring. Br. J. Nutr. 112, 1933-1937. doi: 10.1017/ s0007114514003134

Xian, X., Liu, T., Yu, J., Wang, Y., Miao, Y., Zhang, J., et al. (2009). Presynaptic defects underlying impaired learning and memory function in lipoprotein lipase-deficient mice. J. Neurosci. 29, 4681-4685. doi: 10.1523/jneurosci.029709.2009

Yamazaki, Y., Zhao, N., Caulfield, T. R., Liu, C.-C., and Bu, G. (2019). Apolipoprotein E and Alzheimer disease: pathobiology and targeting strategies. Nat. Rev. Neurol. 15, 501-518. doi: 10.1038/s41582-019-0228-7

Zambrano, E., Martínez-Samayoa, P. M., Rodríguez-González, G. L., and Nathanielsz, P. W. (2010). Dietary intervention prior to pregnancy reverses metabolic programming in male offspring of obese rats. J. Physiol. 588, 17911799. doi: $10.1113 /$ jphysiol.2010.190033 
Zhang, J., and Liu, Q. (2015). Cholesterol metabolism and homeostasis in the brain. Protein Cell 6, 254-264. doi: 10.1007/s13238-014-0131-3

Zhang, Z. Y., Zeng, J. J., Kjaergaard, M., Guan, N., Raun, K., Nilsson, C., et al. (2011). Effects of a maternal diet supplemented with chocolate and fructose beverage during gestation and lactation on rat dams and their offspring. Clin. Exp. Pharmacol. Physiol. 4, 1440-1681.

Zieba, J., Uddin, G. M., Youngson, N. A., Karl, T., and Morris, M. J. (2019). Long-term behavioural effects of maternal obesity in C57BL/6J mice. Physiol. Behav. 199, 306-313. doi: 10.1016/j.physbeh.2018. 11.004
Conflict of Interest: The author declares that the research was conducted in the absence of any commercial or financial relationships that could be construed as a potential conflict of interest.

Copyright $\odot 2021$ Peleg-Raibstein. This is an open-access article distributed under the terms of the Creative Commons Attribution License (CC BY). The use, distribution or reproduction in other forums is permitted, provided the original author(s) and the copyright owner(s) are credited and that the original publication in this journal is cited, in accordance with accepted academic practice. No use, distribution or reproduction is permitted which does not comply with these terms. 